\title{
Psychological Changes and Adaptation: Primary Amenorrhea Associated with Disorders of Sex Development
}

\author{
Kazuyo Iwami ${ }^{1}$, Tomoko Sumiyoshi ${ }^{2} \&$ Shinobu Ida ${ }^{3}$ \\ ${ }^{1}$ Department of Nursing, Faculty of Medical Technology, Teikyo University, Tokyo, Japan \\ ${ }^{2}$ School of Health Sciences, Niigata University, Niigata, Japan \\ ${ }^{3}$ Department of Laboratory Medicine, Osaka Women's and Children's Hospital, Osaka, Japan \\ Correspondence: Kazuyo Iwami, Department of Nursing, Faculty of Medical Technology, Teikyo University \\ 2-11-1 Kaga Itabashi-ku, Tokyo, Japan. Tel: +81-3-3964-1211 Ext. 44512.
}

Received: July 30, 2021 Accepted: September 11, 2021 Online Published: September 13, 2021

doi:10.5539/gjhs.v13n11p1 URL: https://doi.org/10.5539/gjhs.v13n11p1

\begin{abstract}
This qualitative study investigated the psychological changes and process of adaptation among women after a diagnosis of primary amenorrhea associated with disorders of sex development (DSD). Data were obtained of 20 patients aged $\geq 25$ years via interviews and analyzed using the modified grounded theory approach. Six categories were created: increasing doubt about gender identity, questioning and exploratory behaviors, feelings of loneliness and confusion, searching for self with the help of support resources, control for coexistence in society, living at peace with one's body, and liberation from a sense of alien existence. Participants experienced fluctuations in parameters of gender identity, loneliness, and confusion. Encountering good experiences during exploration of helpful resources made them more confident of their female gender identity, thus helping them adapt. For women with primary amenorrhea associated with DSD, the process of becoming liberated from an obsession with their condition after receiving a diagnosis was characterized by the phrase "regaining confidence in being a woman."
\end{abstract}

Keywords: sexual development, gender identity, amenorrhea, women

\section{Introduction}

Disorders of sex development (DSD) are defined as congenital conditions in which the development of the testes, ovaries, and other sex organs is atypical. DSD follow atypical developmental patterns that hinder sexual differentiation based on gender assigned at birth. These abnormal processes in the sexual differentiation mechanism are caused by factors such as genetics. The incidence of DSD is estimated to be 1 in 4500 births. They also affect the development of secondary sex characteristics during puberty (Hughes, Houk, Ahmed, \& Lee, 2006; The Committee on Disorders of Sex Development and Adrenal Disease, the Japanese Society for Pediatric Endocrinology, 2016). The prognosis of DSD is generally favorable. The medical treatment includes hormone replacement therapy and may be surgically treated with genital reconstruction and gonadectomy, performed after considering gonadal function and the risk of malignant transformation. DSD is a medical and social emergency, particularly at birth when gender is assigned. However, the aforementioned treatment strategies have recently been considered a violation of human rights regarding the right to self-determination (Telles-Silveira, Knobloch, \& Kater, 2015). Additionally, DSD are lifelong conditions, and include pubertal developmental disorder, gonadal tumors, gender identity disorder, and infertility, all affecting the quality of life (Ogata, Ida, \& Horikawa, 2011).

DSD conditions have been surrounded by taboo and hesitation among physicians and parents (van Lisdonk, 2014). Moreover, many physicians have not been aware of this issue (The Mainichi Shimbun's project team, 2013). Accordingly, to conform to social norms, individuals tend to hide their condition from others. Thus, the status of patients with DSD is frequently not disclosed (Oyama, 2011). In Japan, nurses have conventionally provided only physical care, making their provision of psychological care inadequate. Even though patients with DSD require careful management, there has been a lack of awareness and support for them within the healthcare system, causing much distress. It usually takes individuals a long time to come to terms with and disclose the reality of their condition. In such cases, appropriate consultation and support by physicians and nurses may enable patients to regain sound mental health, accept themselves, and make their own decisions. 
To address this issue, in 2006, the Lawson-Wilkins Pediatric Endocrine Society (currently known as the Pediatric Endocrine Society) and the European Society for Pediatric Endocrinology (Hughes, Houk, Ahmed, \& Lee, 2006), held an international conference, where worldwide experts gathered and developed a consensus statement for the clinical management of DSD (Consensus on management of intersex disorders). In 2014, the world's first fact-finding survey on DSD patients and their families was conducted in the Netherlands (van Lisdonk, 2014). In Western countries, such as Europe and the United States, patients have access to DSD treatment at medical institutions with teams comprising several healthcare professionals. They also have access to ongoing medical and psychological care programs (McCauley, 2017). In response, guidelines for the initial management of DSD were developed in Japan (The Committee on Disorders of Sex Development, 2011). These guidelines provide information on the chromosomal status and anatomy of the gonads at birth, as related to the diagnosis and treatment of DSD, and recommend psychological care for the parents. Since the release of these guidelines, efforts have been made to standardize and equalize the team-based treatment of DSD to provide psychological care for parents alongside medical aspects of diagnosis and treatment of DSD among newborns. However, guidelines concerning management of patients diagnosed after puberty remain unclear. In fact, many institutions have not adopted team-based care and do not have sufficient experience with these conditions.

Recently, increasing attention has been given to the psychosocial health of patients with DSD and their family members (Bean, Mazur, \& Robinson, 2009; Jurgensen, et al., 2014; Sandberg et al., 2017). The importance of educational support has also been highlighted (McCauley, 2017). However, to the best of our knowledge, no studies have investigated the psychological health of DSD patients in Japan. Moreover, only a few studies have been conducted in Western countries (Callens, Longham, \& Motmans, 2017; Ernst et al., 2016). In the transition from pediatric to adult care, it is essential to increase patients' autonomy and assist them in developing the health literacy skills required in adulthood. The importance of a transition support program, where patients can effectively learn about the condition and its treatment, has been advocated (Betz \& Coyne, 2012). Such support programs should be specific to the needs of patients with DSD because many suffer from gender identity crises that are qualitatively different from those of other patient groups. Therefore, careful explanation and appropriate timing of interventions is necessary.

In this context, it is crucial to create a support system for patients with primary amenorrhea accompanying DSD. Amenorrhea can be divided into primary and secondary presentations. Primary amenorrhea is diagnosed when no menstruation occurs by the age of 13 in women without secondary sexual characteristics, or by the age of 15 in women with secondary sexual characteristics, and is caused by a variety of underlying conditions (Klein et al., 2019). Secondary amenorrhea is a condition in which menstruation does not occur for more than 3 months, mainly from a state of regular menstruation.

Furthermore, it has been suggested that adolescent women with gonadal dysgenesis experience sexual confusion and low self-esteem (Kosteria \& Kanaka-Gantenbein, 2018).

Therefore, we hypothesized that female patients with DSD overcome challenges while experiencing conflicts and confusion during their life stages. We aimed to identify the structure and process of adaptation among DSD patients, including psychological fluctuations, and obtain suggestions for support to help them adapt to their condition.

\section{Method}

\subsection{Study Design}

This qualitative study adhered to the COREQ and SRQR reporting guidelines. We used the modified grounded theory approach (M-GTA; Kinoshita, 2007), based on the grounded theory approach (GTA) designed by Glaser and Strauss (1967). The M-GTA and the GTA share similar basic characteristics: theory generation grounded in data, empiricism, deep interpretations, and verification through application. However, there are two primary differences between these approaches, highlighting the strengths of the M-GTA. First, in the M-GTA, all pieces of recorded interview data are analyzed according to an analytical theme, based on the viewpoints of an "analytically focused person." This helps clarify the focus of the analysis, fiting within a certain range of human actions, recognitions, emotions, and influencing factors. Additionally, individuals in the audience may apply knowledge in actual settings based on their viewpoints (Glaser \& Strauss, 1967; Kambaru, 2018; Kinoshits, 2007). Second, the method of strict coding procedures, based on Strauss's (1987) position that data should be broken down into small chunks, labeled, and coded, is not used. Data interpretations based on worksheet analysis facilitate the direct formation of concepts through M-GTA coding procedures, while a finer fragmentation simply narrows the context 
of participants' statements or actions (Glaser \& Strauss, 1967; Kambaru, 2018; Kinoshita, 2007).

\subsection{Settings and Participants}

Patients who met all the following criteria were included in the study: 1) patients with primary amenorrhea associated with DSD, aged 25-50 years; 2 ) patients belonging to a self-help group for DSD or attending a hospital with sufficient experience in DSD treatment in Kanto and Kansai (among the 28 core hospitals for DSD treatment according to the homepage of the Japanese Society for Pediatric Endocrinology, 2018); and 3) patients who were considered eligible (psychologically stable and able to express their experience) by the representative of the self-help group or the endocrinologist. Regarding the criteria for age, the lower limit was set as the age at which gender identity was established with certainty, and the upper limit was set as the age at which patients began receiving female hormone replacement therapy at the time of the interview (Hattori, 2020). Daily medications may affect gender identity and were associated with the study purpose. We selected this patient population because primary amenorrhea is a rare condition. To enroll an adequate number of patients, we used self-help groups for women with primary amenorrhea associated with disorders of sex development and hospitals often treating patients with DSD. Participants were recruited through contact by self-help groups members and physicians belonging to specialized institutions in Japan who agreed to cooperate. Participants were DSD patients who voluntarily clarified their intention to participate by e-mail or through other means. Additionally, owing to concerns regarding adverse mental health among study participants (as "dishonor" is deeply rooted in the Japanese culture), the ethics committee approved this study on the condition that support systems are made available for patients. Twenty-three women expressed their intention to participate in the study, and 20 women provided consent for participation.

\subsection{Ethical Considerations}

This study was approved by the ethics committees of X University (Approval number: 2018-0169), Y (Approval number 1139), and Z (Approval number 2019 b-57). Participants were provided an oral and written explanation of the study by the research collaborators. The explanation included: the study purpose; an explanation that participation was completely voluntary and participants had the right to refuse to participate and could withdraw at any time without negative consequences, that all information would be kept confidential, and personal information would be protected; and an explanation of the strict data management principles and data destruction after completion of the study and publication of the results. Oral and written informed consent was obtained from each participant.

\subsection{Measurements}

The assessment comprised a semi-structured, one-to-one interview conducted once per participant by a single investigator, using an interview guide (Figure 1). Before the interview, the investigator showed the interview guide to the participants who chose between being asked questions by the investigator or providing information at their discretion. The order of questions was flexible, and questions were asked according to the development and progression of the participants' answers. The interview protocol was designed with reference to "The psychological process of exploring the meaning of life through illness" (O’Connor, Wicker, \& Germino, 1990). The protocol included the concept of "psychological well-being," contributing markedly in the adaptation process (Nishida, 2000). Along with question items, the interview included free discussion of patients' stories from before the diagnostic consultation and thereafter. Furthermore, data on age, diagnosis, visiting medical institutions, family members, job and economic status, and disease information were collected. 
- Around what age did you become concerned about your body or the disease?

- At what age did you learn the name and conditions of the disease? Who explained them to you?

- How did you feel when you learned the name and conditions of the disease? Please describe your feelings in as much detail as possible.

- How did your feelings change afterward? What changed them? Please explain them in as much detail as possible (particularly your feelings when you came to terms with your condition).

- How do you deal with emotional stress and anxiety?

- Whom or what organization did you ask for help? Who or what organization provided support or help to you? In addition, please explain the specific contents of the support that you received.

- Please explain your feelings or perceptions about your current state of self.

- Do you have any dreams, hopes, or goals for the future?

- Please describe your relationship with your family members and friends at present and in the past.

- Have you experienced any painful feelings or experiences during medical examination or in your daily life? If so, please explain them.

- What support did you receive from healthcare providers?

Figure 1. Interview guide

Note. The interview items included: the time of onset of concern about the condition, the time of diagnosis, the person who provided the explanation, the patient's emotional state at the time, coping with their own emotional responses, belief in oneself (self-image), future prospects and hope, the presence or absence of social support and the content of such support, relationships with family members and friends, difficult feelings during medical consultation and in everyday life, and the content of support from healthcare providers.

\subsection{Data Collection and Procedure}

The study period was from November 2018 to May 2020. The research collaborators approached two self-help groups and two medical institutions to participate in the study. Of them, both medical institutions and one self-help group agreed to participate. The interviews were recorded using an integrated chip recorder after obtaining the patients' permission. The interview contents were transcribed verbatim and anonymized. Initially, the study was explained to potential participants by the research collaborators (the representative of the self-help group or the physician at the visiting medical institution).

\subsection{Data Analysis}

The analytically focused persons in this study were women with primary amenorrhea. The analytical theme was "the process of attaining freedom from obsession with the condition after receiving a diagnosis of DSD among women with primary amenorrhea." First, one participant who provided ample and detailed information related to the analysis theme was selected, and concepts were generated from the viewpoint of the analytical theme. Analytical worksheets were created for each concept (name of concept, definition, example, and theoretical memos were entered). Concepts for the analytical worksheets were generated by repeatedly reviewing the interpretation of the recorded data in the analytical meetings. Disagreements were resolved by consensus between the study team. For the second and later cases, a continuous comparative analysis was performed using a comparison of similarities and differences. New concepts were generated while avoiding arbitrary interpretations. Since no new concepts were generated after analyzing the data obtained from 15 participants, five other participants were added to further determine presence of similar or contrasting cases. However, no new concepts were generated after this attempt. The concepts generated from the data of these 20 participants were closely reviewed and were confirmed to be of high quality. After confirming that clear conclusions were drawn from the analytical theme and the setup questions, we concluded that theoretical saturation had been achieved. We then finalized each concept. We ensured that each concept was fully explored after comparing for similarities and differences among the data of the 20 participants. After completing the data analysis, relationships between the generated concepts were examined, and categories were created. Since the explanatory power and range varied among concepts, the concept with a strong explanatory power was not categorized and remained as a concept. Core categories were created using concepts and categories, and their interrelationships were described in the relationship diagram (result diagram; relationships are described in Figure 2). Further, a storyline describing the process was developed. 


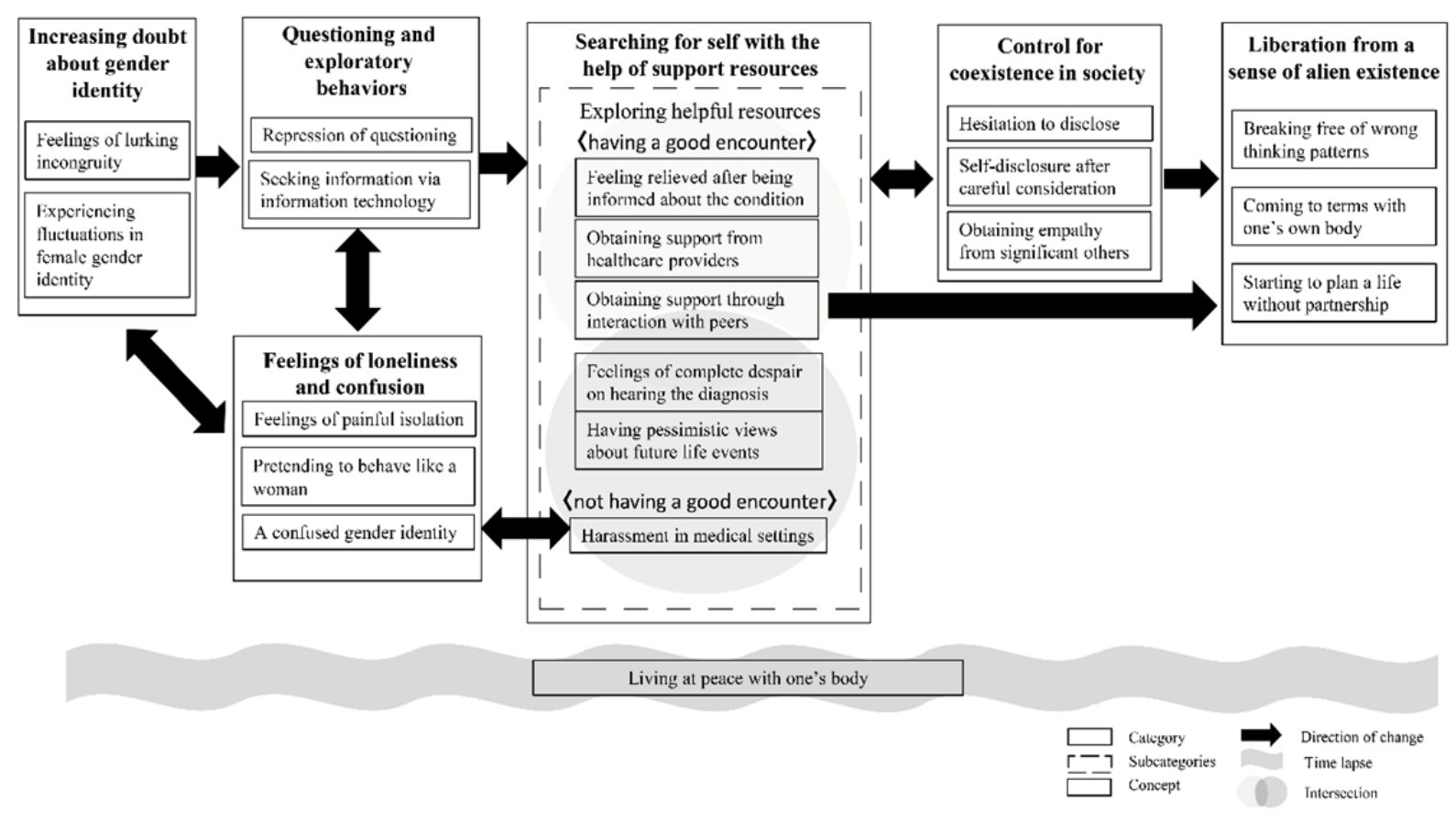

Figure 2. Process of regaining confidence in being a woman

Note. Based on the analysis, 21 concepts were generated. From 20 of these concepts, six categories and one subcategory were created, with an explanatory power as strong as that of the categories. The process of attaining freedom from obsession regarding one's condition after a diagnosis of primary amenorrhea was described as "regaining confidence in being a woman."

To ensure validity, a nursing teacher with experience in qualitative research supervised this study. The recorded interview contents were transcribed verbatim, and the accuracy of the transcripts was checked by the investigators. Additionally, another supervisor who regularly attended the M-GTA study group and had completed the supervisor development course in the study group gave instructions and advice regarding data analysis. The result diagram and storyline were reviewed by two study participants and one research collaborator (physician) to assess potential bias in the data analysis and interpretation of the results.

\section{Results}

\subsection{Participant Characteristics}

From the 23 patients that agreed to participate in the study, 20 patients provided informed consent. Most patients were young and all were $<60$ years of age. Few patients were married. Participants' diagnosis included complete androgen insensitivity syndrome (CAIS; $\mathrm{n}=10$ ), partial androgen insensitivity syndrome (PAIS; $\mathrm{n}=1$ ), 46,XY $\operatorname{DSD}(n=5), 46$, XX DSD $(n=1)$, ovotesticular DSD $(n=1)$, mixed gonadal dysgenesis (MGD; $n=1)$, and Frasier syndrome $(n=1)$. More than half of the patients had undergone gonadectomy. Most participants $(n=18)$ were employed full-time. Most patients $(n=15)$ became concerned when they were 5 th- or 6th-grade elementary school students or junior high school students. The absence of menarche was the most frequent reason for medical consultation $(\mathrm{n}=9)$, excluding cases diagnosed in early childhood. The age at definitive diagnosis varied markedly (16-48 years). More than half $(\mathrm{n}=13)$ had had no accompanying person (parents) at the time of receiving an explanation (Table 1). The mean interview time was 64.6 minutes (range: 42-134 minutes). 
Table 1. Participant characteristics $(\mathrm{N}=20)$

\begin{tabular}{|c|c|}
\hline Characteristics & $\mathrm{n}(\%)$ or mean $\pm \mathrm{SD}$ \\
\hline Age (years) & $33.6 \pm 9.09$ \\
\hline $20 \mathrm{~s}$ & $9(45.0)$ \\
\hline $30 \mathrm{~s}$ & $5(25.0)$ \\
\hline $40 \mathrm{~s}$ & $5(25.0)$ \\
\hline $50 \mathrm{~s}$ & $1(5.0)$ \\
\hline Gender identity (female) & $20(100.0)$ \\
\hline \multicolumn{2}{|l|}{ Diseases } \\
\hline CAIS & $10(50.0)$ \\
\hline 46,XY DSD & $5(25.0)$ \\
\hline PAIS & $1(5.0)$ \\
\hline Ovotesticular DSD & $1(5.0)$ \\
\hline MGD & $1(5.0)$ \\
\hline Frasier & $1(5.0)$ \\
\hline 46,XX DSD & $1(5.0)$ \\
\hline Gonadectomy & $15(75.0)$ \\
\hline Married & $4(20.0)$ \\
\hline \multicolumn{2}{|l|}{ Employment status } \\
\hline full-time employment & $18(90.0)$ \\
\hline part-time employment & $2(10.0)$ \\
\hline \multicolumn{2}{|l|}{ Time of onset of concern about the condition } \\
\hline Elementary school & $5(25.0)$ \\
\hline Junior high school & $10(50.0)$ \\
\hline High school & $3(15.0)$ \\
\hline College & $1(5.0)$ \\
\hline No description & $1(5.0)$ \\
\hline \multicolumn{2}{|l|}{ Reason for consultation } \\
\hline Diagnosed in childhood & $9(45.0)$ \\
\hline Absence of menarche & $9(45.0)$ \\
\hline Others (love affair) & $2(10.0)$ \\
\hline Age at definitive diagnosis & $23.3 \pm 7.98$ \\
\hline Accompanying person at the time of explanation (parents) (absent) & $13(65.0)$ \\
\hline
\end{tabular}

$\mathrm{CAIS}=$ complete androgen insensitivity syndrome, $\mathrm{DSD}=$ disorders of sex development; MGD=mixed gonadal dysgenesis, PAIS $=$ partial androgen insensitivity syndrome, $\mathrm{SD}=$ standard deviation.

\subsection{Storylines}

Based on the analysis, 21 concepts were generated. From 20 of these concepts, six categories and one subcategory were created, with an explanatory power as strong as that of the categories. The relationships between the concepts and processes are shown in Figure 2. The arrows in the figure represent relationships between the concepts and categories, or the direction of change. The storyline was developed as follows: "[ ]" represents category, "( ( ))" represents subcategory, and " $<>$ " represents concepts.

The process of attaining freedom from obsession regarding one's condition after a diagnosis of primary 
amenorrhea was described as "regaining confidence in being a woman."

After puberty, the patients began to compare themselves with their female friends and experienced [increasing doubts about gender identity], such as $<$ feelings of lurking incongruity $>$ and $<$ fluctuations in female gender identity $>$. Since family members or healthcare providers did not educate them about their condition, they feared asking questions and started <seeking information via information technology $>$ while trying to remain calm. However, they experienced more severe isolation due to the insufficiency and inaccuracy of information. They tried to <pretend behaving like a woman> to comply with the socially established gender identity. When the situation became more serious, they experienced feelings of loneliness and confusion, potentially resulting in confused gender identity, and even had doubts about their existence.

Further, they started [searching for self with the help of support resources] and ((exploring helpful resources)). Through good encounters with persons, such as healthcare providers with sufficient knowledge and experience or peers with the same condition, they $<$ felt relieved by being informed about the condition $>$. By facing the facts, including those related to fertility and the $46, \mathrm{XY}$ chromosomal constitution, they were encouraged to move on to the next stage. However, in the absence of good encounters, they fell into a vicious cycle of experiencing [feelings of loneliness and confusion] in response to $<$ harassment in medical settings $>$, such as thoughtless remarks and strange looks from others. In these cases, they were shocked to receive the diagnosis and experienced $<$ feelings of complete despair $>$ upon hearing the diagnosis. In social life, they hesitated to disclose their condition to others, including family members, but they tried to [control for coexistence in society] through $<$ self-disclosure after careful consideration $>$ and $<$ obtaining empathy from significant others $>$. Furthermore, they could $<$ break free of wrong thinking patterns $>$ by having a good encounter, that is, <obtaining support from healthcare providers $>$ and $<$ obtaining support through peer interaction $>$. They tried to $<$ live at peace with their own body $>$ by $<$ coming to terms with their own body $>$ and $<$ starting to plan a life without partnership $>$. In this way, they could achieve [liberation from a sense of alien existence], leading to the holistic mind and body development.

\subsection{Categories and Concepts of the Process}

The following are the categories and concepts of the process, using the participants' narratives. The definitions of the concepts are written in "<>", "Italics" are used for the narrative of the participants, () represents complementary phrases from the investigator, and the parenthesized letter at the end of the sentence represents the ID number of the study subjects.

\subsection{1 [Increasing Doubt about Gender Identity]}

This category was created using two concepts. Patients started to experience $<$ feelings of lurking incongruity $>$. Although aware of the issue, they were reluctant to face it, because it did not interfere with their daily lives: "I knew that something was different. However, it did not interfere with my daily activities. So, I had a vague feeling" (C). The feeling of incongruity gradually increased and brought about serious questions and anxiety. When they faced the absence of secondary sex characteristics after the pubertal period, they <experienced fluctuations in female gender identity $>$. They faced identity issues while experiencing fluctuations in terms of gender identity: " $I$ expected that my breasts would grow when I grew up. However, my expectations were not met. So, I was uncertain about my gender."

\subsection{2 [Questioning and Exploratory Behavior]}

This category was created using two concepts. Patients were worried about their condition but were afraid to ask questions. Moreover, their parents and physicians did not address the issue, leading to an attitude of $<$ repressing their questions $>$. To acquire knowledge, they started <seeking information via information technology $>$ by themselves: "I searched through the internet about what I had been told (at the hospital) and my symptoms, and found out that I have the condition" ( $F)$.

\subsection{3 [Feelings of Loneliness and Confusion]}

This category was created using three concepts. Participants experienced $<$ feelings of painful isolation $>$, including loneliness, solitude, and alienation, because they knew they were physically different from others but did not know anyone like themselves. They thought that people like them are rare and have a different existence. They tried to be feminine by <pretending to behave like a woman> to avoid questioning on their gender identity. When the situation was aggravated, they concluded they lacked (female) gender identity and experienced feelings of serious uncertainty about their existence, <resulting in a confused gender identity>: "In those days, I was thinking that I was the only person in the world born with this condition, and I almost lost hope in life" $(H)$. 


\subsection{4 [Search for Self with the Help of Support Resources]}

This category was created using six concepts, classified into "having a good encounter," "not having a good encounter," and "intersection." The patients were attempting to free themselves from the attitude of emotional repression and confused thinking. They started ((exploring helpful resources)), such as healthcare providers with sufficient knowledge and experience in DSD treatment and peer support groups. By "having a good encounter," they $<$ felt relieved by being informed about the condition $>$. Obtaining a diagnosis, and their shock or confusion upon hearing the diagnosis was attenuated through $<$ obtaining support from healthcare providers $>$. Additionally, they were able to receive useful information and psychological support from members of peer groups for their condition by <providing support through interaction with peers $>$. Those with "no good encounter" experienced $<$ harassment in medical settings $>$, such as thoughtless remarks and strange looks from healthcare providers: "Every time I visited the hospital, they were surprised at me. I felt that I was a guinea pig, rather than a patient. I often got strange looks from nurses and felt that I was treated as a peculiar person $(G)$." The "intersection" is a class of concepts classified as the midpoint or junction between "having a good encounter" and "not having a good encounter" and reflects mental fluctuations before the discovery of support resources. Participants were shocked and despaired as they experienced $<$ feelings of complete despair on hearing the diagnosis $>$. Furthermore, they $<$ had pessimistic views about life events $>$.

\subsection{5 [Control for Coexistence in Society]}

This category was created using three concepts. Since the condition is related to sex and inheritance, they $<$ hesitated to disclose $>$ it not only to their friends and lovers but also to their family members. In contrast, they had an increased need for approval from others and dared to disclose themselves to their close friends and moved on to $<$ self-disclosure after careful consideration $>$. By $<$ obtaining empathy from significant others $>$, they were freed from anxiety and stress. To assist their coexistence in society, some made partial disclosures (e.g., disclosing their infertility while not disclosing the chromosomal constitution), with the aim of avoiding confusion and concern from others: "which is why I do not disclose (to other people). I want to avoid confusion and concerns from others. I avoid disclosure in order to maintain natural relationships (A)."

\subsection{6 [Liberation from a Sense of Alien Existence]}

This category was created using three concepts. They changed their self-recognition and freed themselves from despair and obsession with their hereditary condition $(46, \mathrm{XY})$, which made them $<$ break free of wrong thinking patterns $>$. Through these changes in attitudes, they $<$ came to terms with their own body $>$ : "I cannot have children myself but I imagine that I can live a meaningful life by working for children. That's the way I think now (S)." Through self-reflection and future perspectives, they became stronger and were able to <start planning a life without partnership>.

\subsubsection{Living at Peace with One's Body}

This concept had an explanatory power comparable to that of the other categories. Before and after the definitive diagnosis, they tried to accept their bodies and to live in peace with them.

\section{Discussion}

\subsection{Characteristics of the Adaptation Process among Women with Primary Amenorrhea Associated with DSD}

The adaptation process among women with primary amenorrhea associated with DSD was characterized as follows. They first experienced confusion in gender identity due to the lack of appropriate information and support, leading to pessimistic views and despair about the future. Then, they came to terms with their own bodies by obtaining support from helpful resources and controlling social relationships, including self-disclosure, leading to the reconstruction of identity and regaining confidence in being a woman.

[Searching for self with the help of support resources] was an important category for the adaptation process. After ((exploring helpful resources)), some "had good encounters," while others "did not have good encounters," which affected their adaptation. Obtaining accurate and detailed information from healthcare providers and the presence of a peer support group contributed to overcoming the feeling of isolation and enhancing their psychological support, which is consistent with previous findings (Baratz, Sharp, \& Sandberg, 2014; Cull \& Simmonds, 2010; McCauley, 2017).

Conversely, when they "did not have good encounters," they did not receive accurate diagnosis, adequate information provision, or psychological support, while they may have faced $<$ harassment in medical settings, such as thoughtless remarks and strange looks from healthcare providers and become depressed. This increased their feelings of isolation and may have resulted in a confused gender identity, i.e., they thought that they had a different 
gender identity. They also had doubts about their existence, leading to further confusion. Therefore, ensuring a "good encounter" is a shortcut to adaptation.

However, irrespective of the quality of encounters, they experienced devastation when hearing the diagnosis, including information about infertility and their chromosomal constitution $(46, \mathrm{XY})$. Furthermore, they hesitated or gave up on major life events, such as love and marriage. By "having good encounters," they obtained continuous support from healthcare providers, including an adequate explanation of the condition at an appropriate setting (place and accompanying person), and follow-up. Thus, the shock and confusion on hearing the diagnosis was attenuated, contributing to a deeper understanding of the condition. Furthermore, they achieved [liberation from a sense of alien existence] by obtaining more information and psychological support through interaction with peers.

Patients also tried to [control for coexistence in society] by making a full or partial disclosure, having a social life while living at peace with their own body and becoming free from prejudice. It has been reported that disclosure to others is essential for accepting one's own body and having a positive self-image (MacKenzie, Huntington, \& Gilmour, 2009). However, self-disclosure is arduous for many patients with DSD (Alderson, Madill, \& Balen, 2004; Callens et al., 2017; MacKenzie et al., 2009). In this study, many patients preferred partial disclosure, i.e., disclosing their infertility but not disclosing their chromosomal constitution. Conversely, those who achieved full disclosure experienced being understood by significant others, such as family members, close friends, and lovers, facilitating their process of becoming free from anxiety and stress.

\subsection{From Fluctuations in Gender Identity to "Confidence in Being a Woman"}

Gender is usually assigned at birth, based on the appearance of external genitalia. Children learn about masculinity and femininity as social norms through interactions with parents, teachers, and friends, and exposure to mass media. Typically, they fully accept their gender identity after the development of secondary sex characteristics during puberty (Okamoto \& Matsushita, 2002). Usually, there is no need to question gender identity, and this is also true for children with DSD (Callens et al., 2017; van Lisdonk, 2014). Thus, for most adolescents, gender identity is concordant with the gender assigned at birth. In this study, 19 of the 20 participants had XY chromosomes, and all had a female gender identity. Gender assignment at birth is stressful for some patients with DSD (Thyen, 2014), and in countries such as the Netherlands and Germany, assigning a no-specific-gender identity at birth until the individual makes a decision is recognized. In the future, it is hoped that Japan will also consider such flexible measures. This study showed that DSD is clearly different from gender dysphoria or gender incongruity, although these conditions are often mixed up in our society, including by patients with DSD.

Therefore, women with primary amenorrhea associated with DSD experience marked shock upon hearing that they are infertile and have XY sex chromosomes. This shock is greater than that of realizing the absence of breast development and menarche. Being diagnosed with DSD may affect one's self-image as men or women (Alderson et al., 2004), and cause suffering from an impaired self-image of not being real women (Callens et al., 2017). A positive self-image is constructed by thoughts and feelings about being recognized as "men" or "women" by others. Individuals with DSD are reported to have difficulty developing a positive self-image (MacKenzie et al., 2009; van Lisdonk, 2014). As Japan is a "collectivist" society, Japanese people perceive being different from others as a threat to their cultural values (Suzuki, Ito, Ishida, Nihei, \& Maruyama, 2010). In this context, accurate diagnosis, adequate information provision, and psychological support are essential. In the absence of such support, they may experience confusion about gender identity, develop a negative self-image, give up major life events such as being a woman, and experience [feelings of loneliness and confusion].

Additionally, the degree of satisfaction with medical support is reportedly lower in patients with 46,XY DSD than in those with 46,XX DSD (Thyen, Lux, Jurgensen, Hiort, \& Kohler, 2014). This may be attributed to the fact that most women with 46,XY have not been taught or provided complete explanations about their condition in childhood, and experience incongruity without knowing the reason. They are also psychologically frustrated because they have not received support from their family. The diagnosis of 46,XY DSD is delayed and inaccurate. In some patients, the diagnosis is not made until adulthood (Massanyi, Dicarlo, Migeon, \& Gearhart, 2013; Thyen et al., 2014). In this study, the mean age at the time of full explanation of the condition was 23.5 years (the oldest patient was 48 years old). It has been reported that an early and accurate diagnosis with subsequent explanation may enhance the understanding of the condition and satisfaction with treatment (Massanyi et al., 2013). These patients should be referred to specialized hospitals employing a dedicated team with sufficient experience in DSD treatment. Moreover, a collaborative management is required (Fisher, Ristori, Fanni, Castellini, Forti, Maggi, 2016; Parisi et al., 2007).

Individuals with DSD and their family members seek medical and psychological support from healthcare providers at specialized hospitals. Psychological support is an integral part of support for these patients (Callens et 
al., 2017). Additionally, when providing support, it is essential to provide sufficient information to facilitate the acceptance of their bodies (Alderson et al., 2004; MacKenzie et al., 2009). Healthcare providers should have adequate knowledge and experience in DSD treatment and provide psychosocial support in accordance with the stage of the patient's development, including the transition from pediatric to adult care, from a long-term perspective. In particular, nurses provide the opportunity for patients to 'have good encounters' and play a coordinating role in team-based treatment by making judgments based on their high ethical standards. Nurses also contribute to patient adaptation. Nursing researchers should promote ethical research to investigate gender identity and establish methods of care provision for this patient group. Additionally, this interview study suggested the importance of psychological support through interaction with peers, which is consistent with the findings of previous studies (Alderson et al., 2004; MacKenzie et al., 2009; Schweizer, Brunner, Gedrose, Handford, Hertha, 2017; van Lisdonk, 2014). There is a limited number of peer support groups for DSDs (Lee et al., 2016; Schweizer et al., 2017). Although the participation rate in peer support groups varies, it is higher in women with 46,XY DSD (Okomoto \& Matsushita, 2002). This suggests that interaction with peers with the same condition is particularly useful for these women. Functional psychological support (counseling) and interaction with peers are effective in preventing social isolation and controlling the degree of self-disclosure to others (Callens et al., 2017; Hughes et al., 2006). In the future, close collaboration between healthcare providers and peer support groups may be effective in supporting individuals with DSD and their family members (Iwami, 2019). Through such support, they can avoid fluctuations and confusion about female gender identity and experience relief and a sense of identity (such as "I can be a woman," and "I am a woman"). This may correspond to the "identity adaptation process" described by Corbin (Woog, 1992). Since the adaptation process is continuous, ongoing, long-term support is necessary for them to become completely confident in their female gender identity and liberate themselves from the obsession and adapt better to their condition.

\subsection{Clinical Applications}

This study described the psychological changes and adaptation processes in women with primary amenorrhea accompanying DSD. Based on the analysis of the interview results, we summarized the clinical applications as follows:

(1) Patients experience feelings of uncertainty and incongruity about their condition in the early days. Therefore, early education and support for families (particularly parents) is warranted.

(2) Healthcare providers are expected to provide accurate diagnoses and adequate information regarding the importance of full disclosure. Since the condition is related to sex and gender identity development, a careful approach and continuous psychological support are required.

(3) Most of these patients have a female gender identity. Therefore, healthcare providers should clearly (and repeatedly) state, after diagnosis, that they are definitely women.

(4) Hospitals should provide a consultation service specialized in gender identity and start a comprehensive awareness campaign to eliminate prejudice associated with gender identity and promote understanding of gender diversity in the society.

(5) Healthcare providers are recommended to introduce patients to a peer support group for those willing to participate and collaborate with a peer support group.

\subsection{Limitations and Future Directions}

Approximately $70 \%$ of the participants in this study had contact with specialized hospitals and peer support groups, albeit with some detours. This study only included patients who had access to support systems (according to the conditions of the ethics committee). Therefore, we were unable to target patients from other various environments. Further accumulation of data and validation of the process determined in this study are required. Additionally, the development of information provision tools, such as websites with a list of helpful resources, is warranted.

\section{Conclusion}

Among women, the process of becoming free from obsession over one's condition after receiving a diagnosis of primary amenorrhea associated with DSD is characterized by "regaining confidence in being a woman." This process may be enhanced through raising awareness on the condition and developing medical and social support systems.

\section{Acknowledgments}

The authors thank the study participants and research collaborators for their cooperation and Professor Suemi Nagashima, Okinawa Prefectural College of Nursing, for her supervision of this work. 


\section{Competing Interests Statement}

The authors declare that there are no competing or potential conflicts of interest.

\section{References}

Alderson, J., Madill, A., \& Balen, A. (2004). Fear of devaluation: Understanding the experience of intersexed women with androgen insensitivity syndrome. British Journal of Health Psychology, 9, 81-100. https://doi.org/10.1348/135910704322778740

Baratz, A. B., Sharp, M. K., \& Sandberg, D. E. (2014). Disorders of sex development peer support. Endocrine Development, 27, 99-112. https://doi.org/10.1159/000363634

Bean, E. J., Mazur, T., \& Robinson, A. D. (2009). Mayer-Rokitansky-Kuster-Hauser syndrome: Sexuality. psychological effects, and quality of life. Journal of Pediatric and Adolescent Gynecology, 22, 339-346. https://doi.org/10.1016/j.jpag.2008.11.006

Betz, C. L., \& Coyne, I. T. (2012). Guidebook of transition support for nurses/medical staff involved in transitional care from pediatric to adult services (2nd ed.). New York, NY: Springer.

Callens, N., Longham, C., \& Motmans, J. (2017). Samenvatting intersekse/DSD in Vlaanderen. Gent: UGent \& UZ Gent. http://hdl.handle.net/1854/LU-8521160.Translated by nexdsd Japan. Retrieved August 30, 2020, from: https://www.nexdsd.com/blog

Cull, M. L., \& Simmonds, M. (2010) Importance of support groups for intersex (disorders of sex development) patients, families and the medical profession. Sexual Development, 4, 310-312. https://doi.org/10.1159/000313889

Ernst, M. E., Sandberg, D. E., Keegan, C., Quint, E. H., Lossie, A. C., \& Yashar, B. M. (2016). The lived experience of MRKH: Sharing health information with peers. Journal of Pediatric and Adolescent Gynecology, 29, 154-158. https://doi.org/10.1016/j.jpag.2015.09.009

Fisher, A. D., Ristori, J., Fanni, E., Castellini, G., Forti, G., \& Maggi, M. (2016). Gender identity, gender assignment and reassignment in individuals with disorders of sex development: A major of dilemma. Journal of Endocrinological Investigation, 39, 1207-1224. https://doi.org/10.1007/s40618-016-0482-0

Glaser, B. G., \& Strauss, A. L. (1967). The discovery of grounded theory: Strategies for qualitative research. Chicago, IL: Aldine Publishing Company.

Hattori, S. (2020). The theory of life-span human development (3rd ed.). Tokyo: Igaku syoin.

Hughes, I. A., Houk, C., Ahmed, S. F., Lee, P. A., \& LWPES1/ESPE2 Consensus Group. (2006). Consensus statement on management of intersex disorders. Archives of Disease in Childhood, 91, 554-563. https://doi.org/10.1542/peds.2006-0738

Iwami, K. (2019). Patient/Family meeting. In S.Ida, M. Kawai, F. Matsui, K. Iwami, \& N. Eguchi (Eds.), Let's think about disorders of sex development: for patients, parents and heath care providers (pp. 86-87). Tokyo : Shindan to Chiryo Sha.

Jürgensen, M., Lux, A., Wien, S. B., Kleinemeier, E., Hiort, O., \& Thyem, U. (2014). Health-related quality of life in children with disorders of sex development (DSD). European Journal of Pediatrics, 173, 893-903. https://doi.org/10.1007/s00431-014-2264-z

Kambaru, A. (2018). Qualitative research and a modified grounded theory approach. The Tsuru University Review, 88, 47-58. http://trail.tsuru.ac.jp/dspace/bitstream/trair/871/1/Y-088047.pdf

Kinoshita, Y. (2007). Live lecture: M-GTA (Modified grounded theory approach). Tokyo: Kobundo.

Klein, D. A., Paradise, S. L., \& Reeder, R. M. (2019). Amenorrhea: A Systematic Approach to Diagnosis and Management. American Family Physician, 100, 39-48.

Kosteria, I., \& Kanaka-Gantenbein, C. (2018). Turner Syndrome: transition from childhood to adolescence. Metabolism, 86, 145-153. https://doi.org/10.1016/j.metabol.2017.12.016

Lee, P. A., Nordenstrom, A., Houk, C. P., Ahmed, S. F., Auchus, R., Baratz, A., ... Global DSD Update Consortium. (2016). Global disorders of sex development update since 2006: Perceptions, approach and care. Hormone Research in Pediatrics, 85, 158-180. https://doi.org/10.1159/000442975

MacKenzie, D., Huntington, A., \& Gilmour, J. A. (2009). The experience of people with an intersex condition: A journey from silence to voice. Journal of Clinical Nursing, 18, 1775-1783. 
https://doi.org/10.1111/j.1365-2702.2008.02710.x

Massanyi, E. Z., Dicarlo, H. N., Migeon, C. J., \& Gearhart, J. P. (2013). Review and management of 46,XY disorders of sex development. Journal of Pediatric Urology, 9, 368-379. https://doi.org/10.1016/j.jpurol.2012.12.002

McCauley, E. (2017). Challenges in educating patients and parents about differences in sex development. American Journal of Medical Genetics, Part C, Seminars in Medical Genetics, 175, 293-299. https://doi.org/10.1002/ajmg.c.31563

Nishida, Y. (2000). Studies on diverse lifestyles and psychological well-being of adult women. Japanese Journal of Educational Psychology, 48, 433-443. https://doi.org/10.5926/jjep1953.48.4_433

O'Connor, A. P., Wicker, C. A., \& Germino, B. B. (1990). Understanding the cancer patient's search for meaning. Cancer Nursing, 13, 167-175. https://doi.org/10.1097/00002820-199006000-00006

Ogata, T., Ida, S., \& Horikawa, R. (2011). Disorders of sex development: Classification of social gender assignment. Japanese Journal of Clinical Urology, 65, 897-902.

Okamoto, Y., \& Matsushita, M. (2002). Between femininity and the sense of oneself. In New lifecycle psychology for women. Tokyo: Fukumura Shuppan.

Oyama, K. (2011). Current status of disorders of sex development in Japan: a survey on disorders of sex development. Journal of the Japanese Pediatric Society, 115, 1-4.

Parisi, M., Ramsdell, L., Burns, M., Carr, M., Grady, R., Cunther, D., ... Pagon, R. A. (2007). A Gender Assessment Team: Experience with 250 patients over a period of 25 years. Genetics in Medicine, 9, 348-357. https://doi.org/10.1097/gim.0b013e3180653c47

Sandberg, D. E., Garden, M., Callens, N., Mazur, T., the DSD-TRN Psychosocial Workgroup, the DSD-TRN Advocacy Advisory Network, \& Accord Alliance. (2017). Interdisciplinary care in disorders/differences of sex development (DSD): The psychosocial component of the DSD-Translational research network. American Journal of Medical Genetics. Part C, Seminars in Medical Genetics, 175, 279-292. https://doi.org/10.1002/ajmg.c.31561

Schweizer, K., Brunner, F., Gedrose, B., Handford, C., \& Hertha, R. A. (2017). Coping with diverse sex development treatment experiences and psychosocial support during childhood and adolescence and adult well-being. Journal of Pediatric Psychology, 42, 504-551. https://doi.org/10.1093/jpepsy/jsw058

Strauss, A. L. (1987). Qualitative analysis for social scientists. New York, NY: Cambridge University Press.

Suzuki, M., Ito, M., Ishida, M., Nihei, N., \& Maruyama, M. (2010). Individualizing Japan: Searching for its origin in first modernity. British Journal of Sociology, 61, 513-538. https://doi.org/10.1111/j.1468-4446.2010.01324.x

Telles-Silveira, M., Knobloch, F., \& Kater, C. E. (2015). Management framework paradigms for disorders of sex $\begin{array}{lllll}\text { development. Archives of Endocrinology and Metabolism, } & 38390 .\end{array}$ https://doi.org/10.1590/2359-3997000000084

The Committee on Disorders of Sex Development and Adrenal Disease, the Japanese Society for Pediatric Endocrinology (2016, December 1). In Webtext titled "Diagnosis and treatment of disorders of sex development. Retrieved August 30, 2020, from:

http://jspe.umin.jp/medical/files/webtext_170104.pdf

The Committee on Disorders of Sex Development. (2011). Guidelines for initial management of disorders of sex development [in Japanese]. Tokyo: The Japanese Society for Pediatric Endocrinology. Retrieved August 30, 2020, from: https://jspe.umin.jp/medical/files/seibunkamanual_2011.1.pdf

The Mainichi Shimbun's project team on "Living on the boundaries." (2013). Living on the boundaries: Ways of life and gender identities. Tokyo: The Mainichi Newspapers Co., Ltd.

Thyen, U., Lux, A., Jürgensen, M., Hiort, O., \& Köhler, B. (2014). Utilization of healthcare services and satisfaction with care in adults affected by disorders of sex development (DSD). Journal of General Internal Medicine, 29, S752-S759. https://doi.org/10.1007/s11606-014-2917-7

van Lisdonk, J. (2014). Living with intersex/DSD: An exploratory study of the social situation of persons with intersex/DSD. Den Haag: Sociaal en Cultureel Planbureau. Translated by nexdsd Japan Retrieved August 30, 2020, from https://131e3702-27f0-8862-14ef-b9ddcba3da5b.filesusr.com/ugd/0c8e2d_ 
36b9cbb9aa864fca821ad8bf5ab35b25.pdf

Woog, P. (1992). The chronic illness trajectory framework: The Corbin and Strauss nursing model. New York: Springer Publishing Company.

\section{Copyrights}

Copyright for this article is retained by the author(s), with first publication rights granted to the journal.

This is an open-access article distributed under the terms and conditions of the Creative Commons Attribution license (http://creativecommons.org/licenses/by/4.0/). 